\title{
CRIMES VERDES E COLARINHO BRANCO: A MÁFIA DA MADEIRA NA AMAZÔNIA OCIDENTAL, UMA VIOLAÇÃO AOS DIREITOS HUMANOS
}

\author{
Marco Antonio Domingues Teixeira ${ }^{1}$ \\ Renata Miranda Lima ${ }^{2}$ \\ Julio Cesar de Souza Ferreira ${ }^{3}$
}

\section{Resumo}

O presente artigo trata da ação de organizações criminosas na prática de delitos ambientais na Amazônia ocidental, com foco de pesquisa na extração ilegal de madeira em reservas ambientais localizadas no estado de Rondônia. O objetivo da pesquisa é apresentar o crime ambiental por um prisma ainda não explorado, a ação de grupos e organizações criminosas com alta lucratividade em detrimento do meio ambiente e em prejuízo à população tradicional, o que se traduz em violação a direitos humanos em várias vertentes. A pesquisa é aplicada, de abordagem qualitativa, com levantamento de dados das respectivas delegacias de polícia e pesquisa bibliográfica acerca do tema. Como resultados, conclui-se que a exploração clandestina de madeira em reservas ambientais não é crime eventual ou isolado e sim ação de grupos criminosos de estrutura ordenada com divisão de tarefas, configurando verdadeiras organizações criminosas.

Palavras-chave: Madeira; Amazônia Ocidental; Crimes Ambientais; Organizações Criminosas; População tradicional.

\footnotetext{
${ }^{1}$ Doutor em Ciências Desenvolvimento Socioambientais pela Universidade Federal do Pará. Professor de História da Universidade Federal de Rondônia. E-mail: marcoteixeira204@gmail.com

${ }^{2}$ Aluna do mestrado profissional interdisciplinar em Direitos Humanos e Desenvolvimento da Justiça da Universidade Federal de Rondônia. E-mail: renata.milisofer@gmail.com

${ }^{3}$ Aluno do mestrado profissional interdisciplinar em Direitos Humanos e Desenvolvimento da Justiça da Universidade Federal de Rondônia (DHJUS/UNIR/EMERON).E-mail: julio.cesar.opo@gmail.com
} 


\section{INTRODUÇÃO}

O presente artigo aborda a problemática da devastação da floresta amazônica sob o enfoque das ações de grupos e organizações criminosas, especialmente em reservas ambientais localizadas parte setentrional de estado de Rondônia, um dos estados da Amazônia ocidental.

O objetivo do trabalho é trazer dados acerca da ação das organizações criminosas na exploração ilegal de madeira, o que pode ser chamado de "máfia da madeira", tendo em conta a alta lucratividade desse tipo de empreendimento e a forma estruturada das ações dessas quadrilhas.

O meio ambiente ecologicamente equilibrado é bem jurídico protegido pelo ordenamento pátrio (art. 225 da CR/88) e por tratados e convenções internacionais, também ratificados pela República Federativa do Brasil. Daí a necessidade de proteção suficiente a esse bem jurídico.

Nesse contexto, com a promulgação da lei 9.605/98, o Estado brasileiro avançou na proteção dos bens jurídicos ali tutelados, quais sejam, a fauna, a flora, e meio ambiente artificial, tipificando administrativa e criminalmente condutas lesivas ao meio ambiente. Os crimes contra a flora estão previstos na segunda seção do quinto capítulo desta lei, com pelo menos treze artigos, cujas penas privativas de liberdade variam de seis meses a cinco anos.

A ação de quadrilhas também ganhou nova roupagem no ordenamento brasileiro com a promulgação da lei 12.850/13, a qual definiu e tipificou as chamadas Organizações Criminosas, complementando assim a previsão já existente na convenção de Palermo. Por essa lei, a união de quatro ou mais pessoas, de forma ordenada e com divisão de tarefas, para a prática de crimes cuja pena máxima extrapola quatro anos é conduta típica denominada "Organização Criminosa”.

A extração ilegal de madeira pode configurar, portanto, além de crime ambiental, eventualmente o crime de organização criminosa, pois o extrativista geralmente age sob controle finalístico de empresários do ramo, o que pode se amoldar ao tipo penal de Organização Criminosa (art. 2o da lei 12.850/13), o lucro obtido dessa atividade, por outro lado, caso não declarado ou informado como de origem diversa, pode configurar o crime de lavagem de capitais (art. 10 da lei 9.613/98). Ambos os delitos são comunmente denominados de "colarinho branco" pela doutrina.

Na Amazônia ocidental, especialmente no estado de Rondônia, a incidência desses delitos é muito alta, sendo a extração da madeira em reservas ambientais o principal delito ambiental, ao lado da poluição gerada pelas queimadas.

Dados colhidos em unidades policiais da região conhecida como "vale do Jamari", localizada na parte 
setentrional do estado de Rondônia, ilustram o grande volume e crimes ambientais detectados pelas autoridades policiais, bem como, a quantidade de inquéritos policiais que apuram crimes ambientais perpetrados por organizações criminosas.

A par desses dados, a pesquisa demonstra que a ação de organizações criminosas nessa porção da Amazônia ocidental transpassa os limites da criminalidade controlada e se torna um grave problema de violação sistêmica aos Direitos Humanos.

Além de violar o bem jurídico "meio ambiente", direito fundamental de terceira geração, o crime ambiental também resulta em várias outras violação a direitos humanos catalogados tanto nas convenções internacionais como no ordenamento brasileiro, tendo em vista o rastro de miserabilidade socioeconômica deixado por essa ação criminosa.

Os prejuízos às populações tradicionais são incontáveis, desde o desterro (migração forçada) em razão dos impactos ambientais, até mesmo danos à saúde decorrentes da poluição do ar ou da água.

\section{DIREITO HUMANO AO MEIO AMBIENTE EQUILIBRADO}

Ao falar de direito humano ao meio ambiente necessário conceituar direito humano e suas dimensões. Com efeito, para RAMOS (2017, p. 21) os direitos humanos consistem em um "conjunto de direitos considerado indispensável para uma vida humana pautada na liberdade, igualdade e dignidade. Os direitos humanos são os direitos essenciais e indispensáveis à vida digna.".

O jurista Karel Vasak, durante conferência realizada no ano de 1979, na França, classificou os direitos humanos em três gerações, cada uma com características próprias (RAMOS, 2017, p.53). Posteriormente, determinados autores defenderam a ampliação da dessa classificação para quatro ou até cinco gerações. O direito ao meio ambiente equilibrado estaria incluído nos direitos de terceira geração:

Já os direitos de terceira geração são aqueles de titularidade da comunidade, como o direito ao desenvolvimento, direito à paz, direito à autodeterminação e, em especial, o direito ao meio ambiente equilibrado. São chamados de direitos de solidariedade. São oriundos da constatação da vinculação do homem ao planeta Terra, com recursos finitos, divisão absolutamente desigual de riquezas em verdadeiros círculos viciosos de miséria e ameaças cada vez mais concretas à sobrevivência da espécie humana. (RAMOS, 2017, p.54).

De outro bordo, há que se questionar acerca do fundamento de validade de direitos humanos, tanto do ponto de vista formal, quanto do ponto de vista material. Do ponto de vista formal, um direito seria considerado direito humano ou fundamental se for inserido em texto constitucional ou em tratados internacionais firmados e incorporados, já do ponto de vista material são considerados direitos humanos aqueles que se mostrarem projeção da dignidade humana. 
Nesse contexto, tratemos inicialmente da validade formal do direito ao meio ambiente equilibrado como direito humano. O primeiro evento internacional sobre um meio ambiente equilibrado foi a Conferência de Estocolmo (1972), convocada pela ONU. Esse evento foi um marco na história quanto à busca por equilíbrio entre desenvolvimento econômico e redução da degradação ambiental, e resultou em um documento político de alta relevância denominado Declaração da Conferência das Nações Unidas sobre o Meio Ambiente Humano.

Após esse marco político, novas tratativas e ajustes na comunidade internacional foram paulatinamente alinhavados, surgindo vários tratados e convenções internacionais sobre a matéria. Conforme BRAGA (2011), dentre os pactos, merecem destaque a Convenção sobre Comércio Internacional de Espécies de Flora e Fauna Selvagens em Perigo de Extinção - CITES (1973), a Convenção sobre Poluição Transfronteiriça (1979), a Convenção de Viena para a Proteção da Camada de Ozônio (1985), o Protocolo de Montreal sobre as Substâncias que Esgotam a Camada de Ozônio (1987), a Convenção sobre Controle de Movimentos Transfronteiços de Resíduos Perigosos (Convenção da Basiléia, 1989).

No âmbito da Organização dos Estados Americanos (OEA), após a assinatura da Convenção Americana (também conhecida como pacto de San Jose da Costa Rica) fora adotado o "Protocolo de San Salvador" versando sobre direitos econômicos, sociais e culturais. Nesse documento, precisamente em seu artigo 11, lê-se a seguinte previsão: "1. Toda pessoa tem direito a viver em meio ambiente sadio e a contar com os serviços públicos básicos. 2. Os Estados Partes promoverão a proteção, preservação e melhoramento do meio ambiente."

Ainda do ponto de vista formal, o direito a um meio ambiente equilibrado está inserido também no texto constitucional vigente (art.225 da CRFB/88), sendo uma política de desenvolvimento humano a ser adotada pelo Estado brasileiro, conforme ensina Ingo Sarlet:

O princípio do Estado Democrático de Direito (nas suas diferentes dimensões) é, consoante já visto, um dos princípios fundamentais do constitucionalismo contemporâneo. Mas o Estado Democrático de Direito assumiu e tem assumido diferentes configurações ao longo da evolução do constitucionalismo. Assim, tendo em conta os novos desafios gerados pela crise ecológica e pela sociedade tecnológica e industrial, a configuração de um novo modelo, superando os paradigmas antecedentes, respectivamente, do Estado Liberal e do Estado Social, passou a assumir um lugar de destaque. Entre outras denominações, registram-se as seguintes nomenclaturas para designar a nova "roupagem ecológica" incorporada pelo Estado Democrático de Direito na atualidade, especialmente no âmbito ocidental e tal qual também consagrado pela Constituição Federal de 1988: Estado Póssocial, Estado Constitucional Ecológico, Estado de Direito Ambiental, Estado de Direito Ecológico, Estado Socioambiental, Estado do Ambiente, Estado Ambiental, Estado de BemEstar Ambiental, Estado Verde, Estado de Prevenção e Estado Sustentável. A opção aqui assumida, em sintonia, aliás, com produção acadêmica anterior, pela nomenclatura Estado Socioambiental, busca enfatizar a necessária e urgente convergência das agendas social e ambiental num mesmo projeto jurídico-político para o desenvolvimento humano. (SARLET, MARINONI; MIDIERO, 2015, p. 298) 
Inegável, portanto, que o direito a um meio ambiente equilibrado é reconhecido como direito humano de terceira geração, positivado tanto da ordem internacional como no ordenamento pátrio. Trataremos a seguir da estrutura de proteção ao meio ambiente no ordenamento jurídico brasileiro.

\section{ESTRUTURA DE PROTEÇÃO AO MEIO AMBIENTE NO ORDENAMENTO JURÍDICO BRASILEIRO}

A Constituição Federal de 1988 inovou ao trazer em seu bojo proteção especial ao meio ambiente. As Cartas anteriores previam o meio ambiente equilibrado como consectário da proteção à saúde. No entanto, antes do texto constitucional vigente, já havia no ordenamento a lei da política nacional do meio ambiente, lei no. 6.938/81, a qual foi recepcionada integralmente pela Constituição de 1988.

A lei no. 6.938/81 também trouxe a definição legal de meio ambiente em seu artigo $3^{\circ}$, inciso I, definindoo como "o conjunto de condições, leis, influências e interações de ordem física, química e biológica, que permite, abriga e rege a vida em todas as suas formas." O Código Civil brasileiro de 1916 também já trazia a noção de "bem de uso comum do povo" (art. 66), arrolando os seguintes bens: mares, rios, estradas, ruas e praças.

O sistema constitucional de proteção ao meio ambiente da Constituição Federal de 1988, no entanto, não só tratou o equilíbrio ambiental como prioridade de estado, como também conferiu proteção a esse bem jurídico, inclusive delineando a possibilidade de punição criminal até mesmo de pessoas jurídicas pela prática de delitos ambientais.

\section{Sistema Constitucional de Proteção ao Meio Ambiente}

O capítulo VI do título VIII da Carta Magna de 1988 trata especificamente do meio ambiente. O artigo 225 do texto constitucional prevê que "Todos têm direito ao meio ambiente ecologicamente equilibrado, bem de uso comum do povo e essencial à sadia qualidade de vida, impondo-se ao Poder Público e à coletividade o dever de defendê-lo e preservá- lo para as presentes e futuras gerações." (BRASIL, 1988).

Essa previsão traz o princípio implícito do desenvolvimento sustentável, garantindo-se que a ação humana no meio ambiente seja tal que as futuras gerações também tenham condições de desfrutar os mesmos recursos que está à nossa disposição, conforme leciona o professor Celso Antônio Pacheco Fiorillo:

Constata-se que os recursos ambientais não são inesgotáveis, tornando-se inadmissível que as atividades econômicas desenvolvam-se alheias a esse fato. Busca-se com isso a coexistência harmônica entre economia e meio ambiente. Permite-se o desenvolvimento, mas de forma sustentável, planejada, para que os recursos hoje existentes não se esgotem ou 
tornem-se inócuos. Dessa forma, o princípio do desenvolvimento sustentável tem por conteúdo a manutenção das bases vitais da produção e reprodução do homem e de suas atividades, garantindo igualmente uma relação satisfatória entre os homens e destes com o seu ambiente, para que as futuras gerações também tenham oportunidade de desfrutar os mesmos recursos que temos hoje à nossa disposição. (FIORILLO, 2013, p.57)

O meio ambiente é citado também no texto constitucional no que toca à distribuição de competências federativas (art. 23, VI e VII; art. 24, VIII), nos princípios da ordem econômica e financeira (art. 170, VI; art. 174, \& $3^{\circ}$ ) e ainda ao inserir o ambiente de trabalho no conceito do meio ambiente (art. 200, VIII), bem como, ao incluir no conceito de patrimônio cultural brasileiro os sítios de valor ecológico (art. 216, V) (CARVALHO, 2001, p. 415).

Quanto à maior proteção criminal ao bem jurídico ambiental, a Constituição de 1988 traz a seguinte previsão: "As condutas e atividades consideradas lesivas ao meio ambiente sujeitarão os infratores, pessoas físicas ou jurídicas, a sanções penais e administrativas, independentemente da obrigação de reparar os danos causados" (art. 225, $\$ 3^{\circ}$, da CF).

\section{Proteção Criminal do Meio Ambiente}

Com a previsão do artigo $225, \$ 3^{\circ}$ a Carta Magna inovou e trouxe a base necessária para a punição criminal até mesmo de pessoas jurídicas pela prática de crimes ambientais, enrijecendo o tratamento jurídico aos infratores ambientais. Com efeito, essa nova diretriz orientou a edição do principal diploma repressivo na seara ambiental, a chamada lei de crimes ambientais (lei no.9605), promulgada em 12 de fevereiro de 1998, a qual prevê o seguinte:

Art. 2० Quem, de qualquer forma, concorre para a prática dos crimes previstos nesta Lei, incide nas penas a estes cominadas, na medida da sua culpabilidade, bem como o diretor, o administrador, o membro de conselho e de órgão técnico, o auditor, o gerente, o preposto ou mandatário de pessoa jurídica, que, sabendo da conduta criminosa de outrem, deixar de impedir a sua prática, quando podia agir para evitá-la.

Art. $3^{\circ}$ As pessoas jurídicas serão responsabilizadas administrativa, civil e penalmente conforme o disposto nesta Lei, nos casos em que a infração seja cometida por decisão de seu representante legal ou contratual, ou de seu órgão colegiado, no interesse ou benefício da sua entidade.

Parágrafo único. A responsabilidade das pessoas jurídicas não exclui a das pessoas físicas, autoras, co-autoras ou partícipes do mesmo fato. (BRASIL, 1998)

Necessário aqui a conceituação de crime ambiental. Como não há diferenças ontológicas entre um delito ambiental e qualquer outro, valemo-nos da definição geral acerca de crime, segundo a qual crime é toda conduta humana típica, ilícita e culpável, que, nesse caso em específico, atinge um bem jurídico ambiental.

Entretanto, antes de se esmiuçar as previsões da lei de crimes ambientais, mister tratar do próprio conceito de bem jurídico ambiental para tutela do direito penal. Como é cediço, o direito penal segue princípios 
únicos de aplicação, logo, as mesmas regras para aplicação de quaisquer outras sanções criminais também se aplicam aos crimes ambientais. Ocorre que, na questão ambiental ainda há outros princípios mais que se somam aos já conhecidos.

Nessa toada, entram em cena os princípios ambientais da precaução e da prevenção, que orientam também a lei de crimes ambientais. Conforme leciona Paulo Leme Machado:

A Constituição incorporou a metodologia das medidas liminares, indicando o periculum in mora como um dos critérios para antecipar .-. ação administrativa eficiente para proteger o homem e a biota. Se a constituição não mencionou expressamente o princípio da precaução (que manda prevenir mesmo na incerteza do risco), é inegável que a semente desse princípio está contida no art. 225, \$12, V e VII, ao obrigar à prevenção do risco do dano ambiental. [...] Diz a Constituição: "Para assegurar a efetividade desse direito incumbe ao Poder Público: (...) VII - proteger a fauna e a flora, vedadas,na forma da lei, as práticas que coloquem em risco sua função ecológica, provoquem a extinção de espécies ou submetam os animais a crueldade".(MACHADO,2013, p.165)

Assim, a lei 9.605/98 traz inúmeras previsões de crimes de perigo, com vistas a fazer valer os princípios da prevenção e da precaução, evitando-se assim que atividades potencialmente lesivas ao meio ambiente sejam levadas a cabo. Com o desrespeito às normas administrativas ambientais, as sanções penais são desde logo aplicadas ao infrator que degrada o meio ambiente.

Os crimes contra a flora, nesse contexto seguem a lógica da prevenção e precaução, e tipos penais como ingresso em unidade de conservação (art. 52), ou ainda soltar balões (art. 42) são considerados pela doutrina como crimes de perigo. Além desses, os crimes de poluição também podem ser considerados crimes de perigo.

Outra discussão existente é sobre a aplicação ou não do princípio da insignificância aos crimes ambientais, autores como Vladimir Passos de Freitas e Gilberto Passos de Freitas admitem a aplicação do referido princípio com reservas e em situações excepcionais, conforme segue:

o magistrado, para rejeitar uma denúncia ou absolver o acusado, deverá explicitar, no caso concreto, porque a infração não tem significado. Por exemplo, em crime contra a fauna não basta dizer que é insignificante o abate de um animal. Precisa deixar claro, entre outras coisas, que este mesmo abate não teve influência no ecossistema local, na cadeia alimentar, analisar a quantidade de espécimes na região e investigar se não está relacionado entre os que se acham ameaçados de extinção. (FREITAS, V; FREITAS, G., 2001, p. 45).

O Supremo Tribunal Federal também já admitiu a aplicação do referido princípio (HC 112563, julgado em 21/08/2012), bem como o Superior Tribunal de Justiça (HC 143208/SC julgado em 25/05/2010). Logo, ao que parece seria uma discussão superada a aplicação ou não da insignificância aos delitos ambientais, seguindose assim as mesmas diretrizes para aplicação desse princípio aos demais tipos penais.

Nesse ponto, vale dizer que a degradação ambiental levada a cabo pela extração ilegal de madeira na Amazônia em nenhuma hipótese pode ser considerada insignificante, tendo em vista a potencialidade lesiva da conduta e os resultados de grande monta, bem como, a continuidade delitiva dos infratores. 


\section{CRIMES CONTRA A FLORA}

Os crimes contra a flora estavam tipificados na lei federal 4.771/65 (Código Florestal), no entanto, com o advento da lei de crimes ambientais (9.605/98), aquelas previsões foram tacitamente revogadas. Hoje os delitos contra a flora estão previstos na segunda seção do capítulo $\mathrm{V}$ da lei de crimes ambientais (art. 38 a art. 53).

O novo Código Florestal (lei 12.651/12) não se imiscuiu na seara criminal, inclusive faz alusão (em seu artigo 60) à lei 9.605/98 ao tratar sobre a suspensão de punibilidade de alguns crimes contra a flora. Logo, essa a única previsão criminal existente na atualidade para crimes contra a flora.

Os crimes conta a flora são os seguintes (BRASIL, 1998): Destruir ou danificar floresta considerada de preservação permanente (Art. 38), Cortar árvores em floresta considerada de preservação permanente (Art. 39), Causar dano às unidades de conservação (Art. 40), Provocar incêndio em mata ou floresta (Art. 41), Fabricar, vender, transportar ou soltar balōes (Art. 42), Extração ilegal de mineral em florestas de domínio público (Art. 44), Cortar ou transformar em carvão madeira de lei (Art. 45), Receber, Adquirir ou transportar produtos de origem vegetal de forma irregular (Art. 46 e seu parágrafo único), Impedir ou dificultar a regeneração natural de florestas (Art. 48), Destruir plantas de ornamentação (Art. 49),Destruir ou danificar florestas protetoras de mangues (Art. 50), Desmatar, explorar economicamente ou degradar florestas de domínio público sem autorização (Art. 50A),Utilizar motosserra sem licença (Art. 51) e Penetrar em unidades de conservação conduzindo instrumentos próprios para caça ou extração ilegal (Art. 52).

Ocorre que a maior parte desses crimes tem pena máxima cominada igual ou inferior a dois anos, sendo considerados, portanto, crimes de menor potencial ofensivo (DE LIMA, 2016, p.199) o que ensejaria a aplicação das medidas da lei 9.099/95 (JECRIM). Ou seja, para uma parte desses crimes não se impõe sequer a prisão em flagrante ao infrator. São delitos de menor potencial ofensivo aqueles previstos nos artigos 44, 45, 46, 48, 49, 50,51 e 52 da lei de crimes ambientais.

Como crime de menor potencial ofensivo, colacionamos a lição de Aury Lopes Junior:

Cumpre advertir que, com o advento da Lei n. 9.099/95 e a posterior alteração do art. 61 pela Lei n. 11.313/2006, são consideradas infrações penais de menor potencial ofensivo as contravenções penais e os crimes a que a lei comine pena máxima não superior a 2 anos, cumulada ou não com multa. Não existe mais nenhuma restrição aos crimes a que a lei preveja procedimento especial, como na redação original da Lei n. 9.099. Com isso, diminuiu sensivelmente a incidência de inquérito policial em crimes dessa natureza, posto que, nesses casos, não haverá inquérito policial, mas mero termo circunstanciado. (LOPES JR, 2016, p.99)

Apenas a título de exemplo, o empresário madeireiro flagrado pela fiscalização ambiental recebendo madeira ilegalmente extraída, mesmo que de forma reiterada, não pode sequer ser autuado em flagrante e levado 
ao cárcere, pois incorre no delito do artigo 46 da lei de crimes ambientais, sendo considerada essa infração de menor potencial ofensivo.

Por outro lado, ainda no campo da ilustração, para demonstrar a injustiça social que predomina na aplicação da lei de crimes ambientais, caso um indivíduo seja capturado serrando árvores em floresta sem autorização legal, a mando do empresário hipotético mencionado no parágrafo anterior, esse cidadão será conduzido e autuado em flagrante delito como incurso no artigo 39 da lei 9.605/98, recolhido ao cárcere e sujeito a uma pena de até 03 (três) anos de detenção.

Figura 1 - Indivíduo flagrado cortando árvore dentro de unidade de conservação.

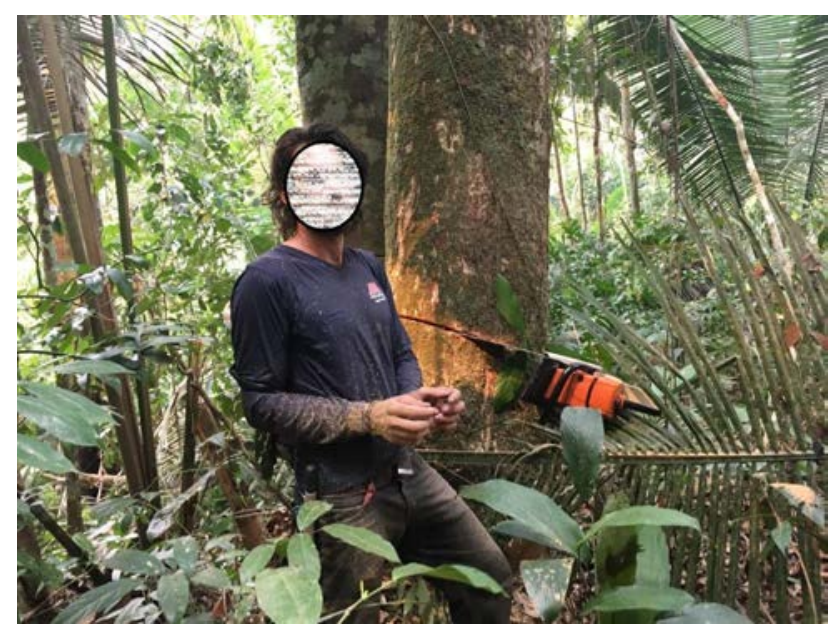

Fonte: Pesquisa de campo junto aos policiais civis envolvidos

Para melhor compreensão dos tipos penais descritos nessa lei, faz-se necessário o esclarecimento acerca dos termos "área de preservação permanente" e "unidade de conservação", tendo em vista que os tipos penais em questão, por preverem conceitos abertos, são normas penais em branco (GUEIROS e JAPIASSÚ, 2012, p. 94).

O conceito de área de preservação permanente, desse modo, é um conceito legal constante do novo código floresta, com a seguinte normatização (BRASIL, 2012):

Art. 3o Para os efeitos desta Lei, entende-se por:

[...]

II - Área de Preservação Permanente - APP: área protegida, coberta ou não por vegetação nativa, com a função ambiental de preservar os recursos hídricos, a paisagem, a estabilidade geológica e a biodiversidade, facilitar o fluxo gênico de fauna e flora, proteger o solo e assegurar o bem-estar das populações humanas; (BRASIL, 2012)

A ideia de preservação dessas áreas não é vinculada apenas às florestas, mas a todos os recursos ambientais disponíveis, conforme a melhor doutrina:

Quanto a essas áreas, o uso da expressão "Áreas de Preservação Permanente" tem sua razão, 
"pois é um espaço territorial em que a floresta ou a vegetação devem estar presentes. Se a floresta aí não estiver, ela deve ser aí plantada. A ideia da permanência não está vinculada só à floresta, mas também ao solo, no qual ela está ou deve estar inserida, e à fauna (micro ou macro). Se a floresta perecer ou for retirada, nem por isso a área perderá sua normal vocação florestal”. A tutela compreende não somente a área e a vegetação nativa ali presentes, mas também a sua função ambiental. A APP é um dos bens do patrimônio ecológico responsável pela proteção das águas, do solo, da biodiversidade, especialmente por assegurar o fluxo gênico da fauna e da flora, da paisagem e do bem-estar humano. (LEHFELD; CARVALHO, 2015, p. 60)

O conceito de Unidade de Conservação - UC, também é um conceito legal, constante da lei federal nº. 9.985/00, diploma que regulamenta o texto constitucional e institui o Sistema Nacional de Unidades de Conservação - SNUC. A referida lei traz as seguintes definições:

Art. 2० Para os fins previstos nesta Lei, entende-se por:

I - unidade de conservação: espaço territorial e seus recursos ambientais, incluindo as águas jurisdicionais, com características naturais relevantes, legalmente instituído pelo Poder Público, com objetivos de conservação e limites definidos, sob regime especial de administração, ao qual se aplicam garantias adequadas de proteção; [...]

VI - proteção integral: manutenção dos ecossistemas livres de alterações causadas por interferência humana, admitido apenas o uso indireto dos seus atributos naturais; [...]

XIII - recuperação: restituição de um ecossistema ou de uma população silvestre degradada a uma condição não degradada, que pode ser diferente de sua condição original; (BRASIL, 2000)

A par desses conceitos, verifica-se que os crimes de maior relevo contra a flora são aqueles que atingem as Unidades de Conservação - UC e as Áreas de Preservação Permanente - APP, cujo dano ambiental é mais prejudicial ao bioma respectivo.

Para prática dessas condutas, em algumas circunstancias os infratores também ocupam áreas consideradas terras públicas, o que faz incidir a tipicidade penal do artigo 20 da lei no $.4 .947 / 66$, cuja previsão é a seguinte: “Art. 20 - Invadir, com intenção de ocupá-las, terras da União, dos Estados e dos Municípios: Pena: Detenção de 6 meses a 3 anos." (BRASIL,1966)

Os crimes mais danosos ao bioma floresta amazônica, nesse contexto, são aqueles que agridem Áreas de Preservação Permanente ou Unidades de Conservação, ao passo que os delitos agrários são também comuns nessa porção geográfica. Nesse contexto, a ação de organizações criminosas na área potencializa o dano ambiental e dificulta a repressão a esse tipo de crime.

\section{CONCEITUANDO ORGANIZAÇÃO CRIMINOSA E CRIME DE COLARINHO BRANCO}

O conceito de crime organizado não é definido pela doutrina e nem tampouco pela jurisprudência, e sim por normas legais ou convencionais sobre o tema. A primeira norma a tratar de crime organizado no 
ordenamento brasileiro foi a lei 9.034, publicada em 03 de maio de 1995, no entanto não trouxe um conceito do que seria organização criminosa.

A lei 9.034/95 vigorou até a publicação e vigência da lei 12.850 de 2013, sendo duramente criticada durante todo o prazo de sua vigência, por ser incompleta e imprecisa, justamente por não conceituar a organização criminosa. Somente em 2004 o Brasil aderiu também à Convenção de Palermo (Promulga a Convenção das Nações Unidas contra o Crime Organizado Transnacional), o qual descreveu um conceito para "grupo criminoso organizado", no seguinte teor:

\section{Artigo 2 - Terminologia}

Para efeitos da presente Convenção, entende-se por:

a) "Grupo criminoso organizado" - grupo estruturado de três ou mais pessoas, existente há algum tempo e atuando concertadamente com o propósito de cometer uma ou mais infrações graves ou enunciadas na presente Convenção, com a intenção de obter, direta ou indiretamente, um benefício econômico ou outro benefício material;

b) "Infração grave" - ato que constitua infração punível com uma pena de privação de liberdade, cujo máximo não seja inferior a quatro anos ou com pena superior;

c) "Grupo estruturado" - grupo formado de maneira não fortuita para a prática imediata de uma infração, ainda que os seus membros não tenham funções formalmente definidas, que não haja continuidade na sua composição e que não disponha de uma estrutura elaborada; (BRASIL, 2004)

O conceito trazido pela Convenção de Palermo foi aplicado no Brasil até 24 de julho de 2012, quando foi publicada a lei no. 12.694, que entrou em vigor 90 dias depois. Essa lei definiu o processo e julgamento de crimes praticados por organizações criminosas, e deu nova definição ao conceito de organização criminosa, senão vejamos:

Art. 2. Para os efeitos desta Lei, considera-se organização criminosa a associação, de 3 (três) ou mais pessoas, estruturalmente ordenada e caracterizada pela divisão de tarefas, ainda que informalmente, com objetivo de obter, direta ou indiretamente, vantagem de qualquer natureza, mediante a prática de crimes cuja pena máxima seja igual ou superior a 4 (quatro) anos ou que sejam de caráter transnacional. (BRASIL, 2012)

Em agosto de 2013 foi promulgada a lei 12.850, a qual entrou em vigor em 17 de setembro do mesmo ano, norma que define organização criminosa e dispõe sobre a investigação criminal, os meios de obtenção da prova, infrações penais correlatas e o procedimento criminal. A definição de organização criminosa desde então passou a ser a seguinte:

Art. 1o Esta Lei define organização criminosa e dispõe sobre a investigação criminal, os meios de obtenção da prova, infrações penais correlatas e o procedimento criminal a ser aplicado.

S 10 Considera-se organização criminosa a associação de 4 (quatro) ou mais pessoas estruturalmente ordenada e caracterizada pela divisão de tarefas, ainda que informalmente, com objetivo de obter, direta ou indiretamente, vantagem de qualquer natureza, mediante a prática de infrações penais cujas penas máximas sejam superiores a 4 (quatro) anos, ou que sejam de caráter transnacional. (BRASIL, 2013)

Essa lei também criou o tipo penal de mesmo nome, prevendo pena de 02 (dois) a 08 (oito) anos de 
reclusão para aquele que promover, constituir, financiar ou integrar, pessoalmente ou por interposta pessoa, organização criminosa, além da pena prevista para os demais delitos perpetrados pela organização.

Os requisitos para configuração de uma Organização Criminosa, portanto, passam a ser vários e específicos, conforme a doutrina pátria:

São requisitos para que se caracterize a criminalidade organizada:

a) Associação (reunião com ânimo associativo, que é diferente de simples concurso de pessoas) de quatro ou mais pessoas. b) Estrutura ordenada que se caracteriza pela divisão de tarefas ainda que informalmente. c) $\mathrm{O}$ fim de obtenção de vantagem de qualquer natureza (portanto, não apenas a econômica) mediante a prática de crimes (excluídas as contravenções). d) Crimes punidos, na pena máxima, com mais de quatro ou que os crimes tenham caráter transnacional, independentemente da quantidade da pena.

A doutrina enumera características para a identificação de uma organização criminosa que continuam como parâmetros de orientação para a identificação dos requisitos agora legais e que são os seguintes:

a) Estrutura organizacional, com células relativamente estanques, de modo que uma não tem a identificação dos componentes da outra. b) Especialização de tarefas, de modo que cada uma exerce uma atividade predominante. Tomando como exemplo uma organização criminosa para o tráfico ilícito de entorpecentes, dir-se-ia que tem ati-vidade definida o importador, o transportador, o destilador, o financeiro, o traficante de área e distribuidor e o traficante local, como uma rede, das artérias aos vasos capilares. c) A existência de vários níveis de hierarquia, em que os subordinados nem sempre, ou quase nunca, conhecem a identidade da chefia de dois ou mais escalóes superiores ou ainda que conheçam a chefia mais elevada não têm contato direto com ela e não podem fornecer provas a respeito. d) A possível existência de infiltração de membros da organização em atividades públicas, nos Poderes Executivo, Legislativo, Ministério Público e Judiciário e corrupção de agentes públicos. e) A tendência de durabilidade. f) A conexão com outras organizações, no mesmo ramo ou em ramo diferente, quando não a atividade em vários ramos. g) A coação, mediante violência, chantagem ou aproveitamento da condição de pessoas não participantes, mas que passam a ser auxiliares ou coniventes e que vivem sob a imposição de grave dano em caso de delação. h) Mais de três pessoas. (GRECO FILHO, 2014, p.22)

Os critérios fundamentais para definição de organização criminosa são a estrutura ordenada e a divisão

de tarefas, pois a associação de pessoas pode configurar o crime do artigo 288 do Código Penal (associação criminosa).

Por outro lado, um conceito bastante utilizado é o conceito de "crime de colarinho branco", que no mais das vezes pode ser confundido com o termo "organização criminosa".

O termo "crime de colarinho branco" (em original "white collar crime") foi criado pelo americano Edwin Sutherland, em 1939 e expressão usada por Sutherland objetivava definir "a atividade ilegal de pessoas de nível socioeconômico superior, relacionado com as práticas normais de seus negócios." (PIMENTEL, 1974).

Muito se discute sobre a abrangência desse termo, no entanto a expressão é comumente utilizada para designar a ação ou comportamento reprovável do homem de negócios que obtém vantagem indevida e causa danos à coletividade por seu desvio de conduta profissional e ética (PIMENTEL, 1974).

Especificamente com relação ao delito ambiental, em junho de 2017, durante Conferência Global de 
Crimes Florestais convocada pela Organização Internacional de Polícia Criminal (INTERPOL) ${ }^{4}$, os conferencistas chegaram ao acordo de que o delito ambiental transnacional seria modalidade de "crime do colarinho branco" e ameaça global a ser fortemente combatida ${ }^{5}$.

Nessa conferência foi esclarecido que o comércio ilegal de madeiras movimenta anualmente cerca de 50 bilhões de dólares. A conferência teve a participação de representantes de cerca de 40 países membros da INTERPOL na África, nas Américas, na Ásia e na Europa, e ao final foi estabelecido um grupo especializado em crime internacional contra crimes florestais.

Nesse contexto, nem toda organização criminosa pratica crimes de colarinho branco e tampouco todo criminoso de colarinho branco é integrante de organização criminosa, contudo, no Brasil especialmente, os crimes de lavagem de capitais e os crimes ambientais tendem a ser perpetrados por organizações criminosas e classificados como crimes de colarinho branco, inclusive pela INTERPOL.

\section{EXTRAÇÃO ILEGAL DE MADEIRA NA AMAZÔNIA A MÁFIA DA MADEIRA}

Em que pese a existência de uma rígida legislação ambiental, que regula e autoriza a exploração de madeira de forma lícita, em áreas específicas, a extração ilegal de madeira é uma prática difundida em toda a Amazônia, não só no Brasil. Na área da Amazônia ocidental, contudo, essa prática tem se intensificado nos últimos anos. Dados do Instituto Nacional de Pesquisa Espacial evidenciam um aumento do desmatamento nos últimos anos.

O estado de Rondônia foi um dos mais atingidos pela exploração ilegal de madeira nos últimos anos, por exemplo, no parque estadual Guajará-mirim, uma das áreas de preservação permanente, o desmatamento disparou nos últimos anos ${ }^{6}$ de acordo com dados do Instituto Nacional de Pesquisa Espacial.

\footnotetext{
${ }^{4}$ INTERPOL é a maior organização policial internacional do mundo, com 192 países membros.

5 Notícia no sítio de internet da INTERPOL, disponível no link <https://www.interpolint/News-andmedia/News/2017/N2017-082> Acesso em 23 de setembro de 2018
} 
Figura 2 - Imagem do desmatamento na Amazônia

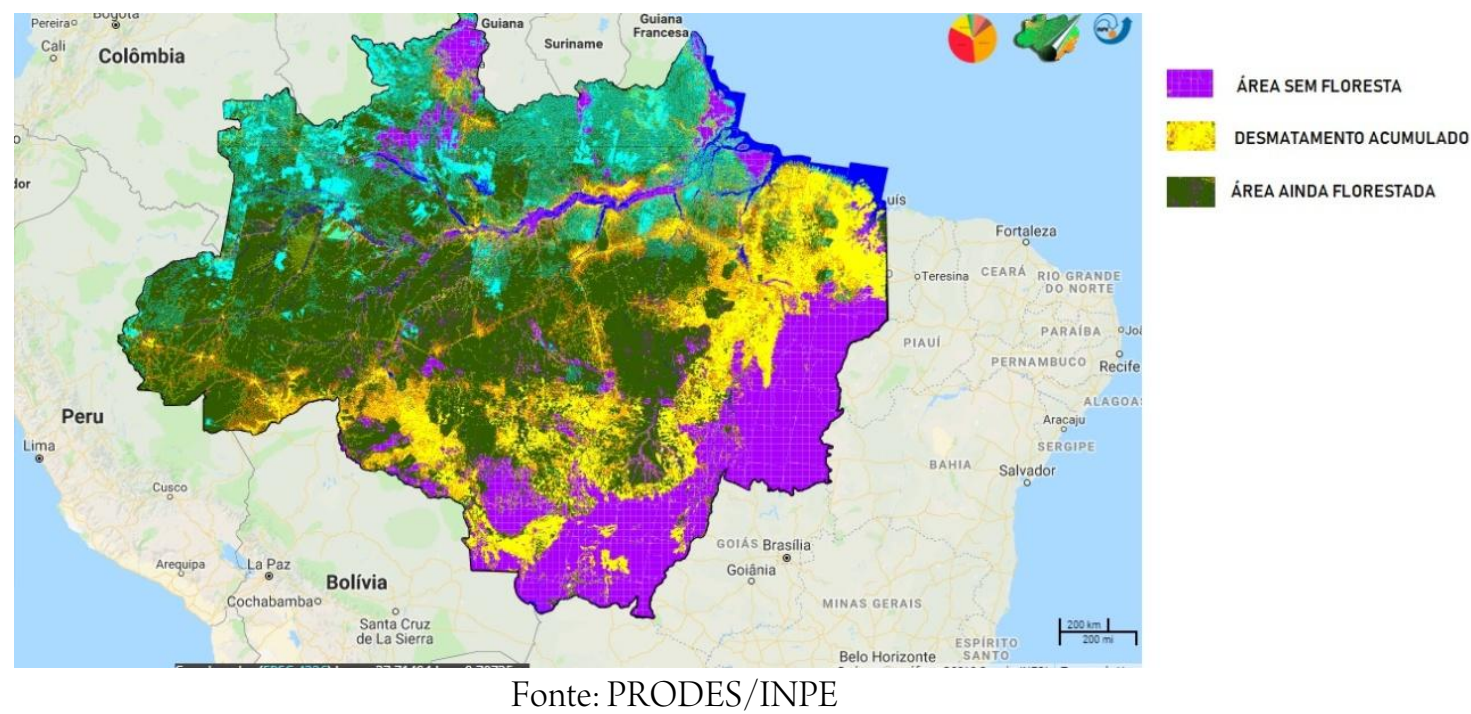

De acordo com a organização não governamental WWF Brasil7, as operações extrativas ilegais acontecem em áreas florestais remotas e caracterizam-se por qualquer um dos seguintes aspectos: uso de licenças falsas, corte de qualquer árvore comercialmente valiosa, independentemente de quais árvores sejam protegidas por lei, corte em quantidades superiores às cotas permitidas por lei, corte fora de áreas de concessão florestal, corte dentro unidades de conservação e terras indígenas.

As informações dessa organização vão ao encontro do que afirmam as autoridades policiais do estado de Rondônia. No último semestre de 2017 e no primeiro quadrimestre de 2018, a Secretaria de Desenvolvimento Ambiental do Estado de Rondônia (SEDAM) juntamente com a Polícia Civil do Estado de Rondônia (PCRO) atuaram em parceria no formato força-tarefa ${ }^{8}$ para combate aos crimes ambientais na região mais crítica desse estado, a região conhecida como vale do Jamary.

\footnotetext{
6 Notícia veiculada pela revista Época, disponível no link < https://epoca.globo.com/ciencia-e-meioambiente/noticia/2018/01/em-rondonia-desmatamento-e-caso-de-policia.html> Acesso em 23 de setembro de 2018.

7 Notícia disponível no site da WWF Brasil, disponível no link < https://www.wwf.org.br/natureza_brasileira/areas_prioritarias/amazonia1/ameacas_riscos_amazonia/desmatamento_na_am azonia/extracao_de_madeira_na_amazonia/> Acesso em 23 de setembro de 2018.

${ }^{8}$ Notícia da atuação conjunta no próprio site oficial da Polícia Civil do Estado de Rondônia, disponível no link< http://www.pc.ro.gov.br/news/policia-civil-e-sedam-deflagram-operacao-cyber-cupim-no-vale-do-jamary-20180403-12489.html >. Acesso em 23 de setembro de 2018.
} 
Figura 3 - Equipe de policias e técnicos da SEDAM reunidos após operação policial da força-tarefa Vale do Jamary

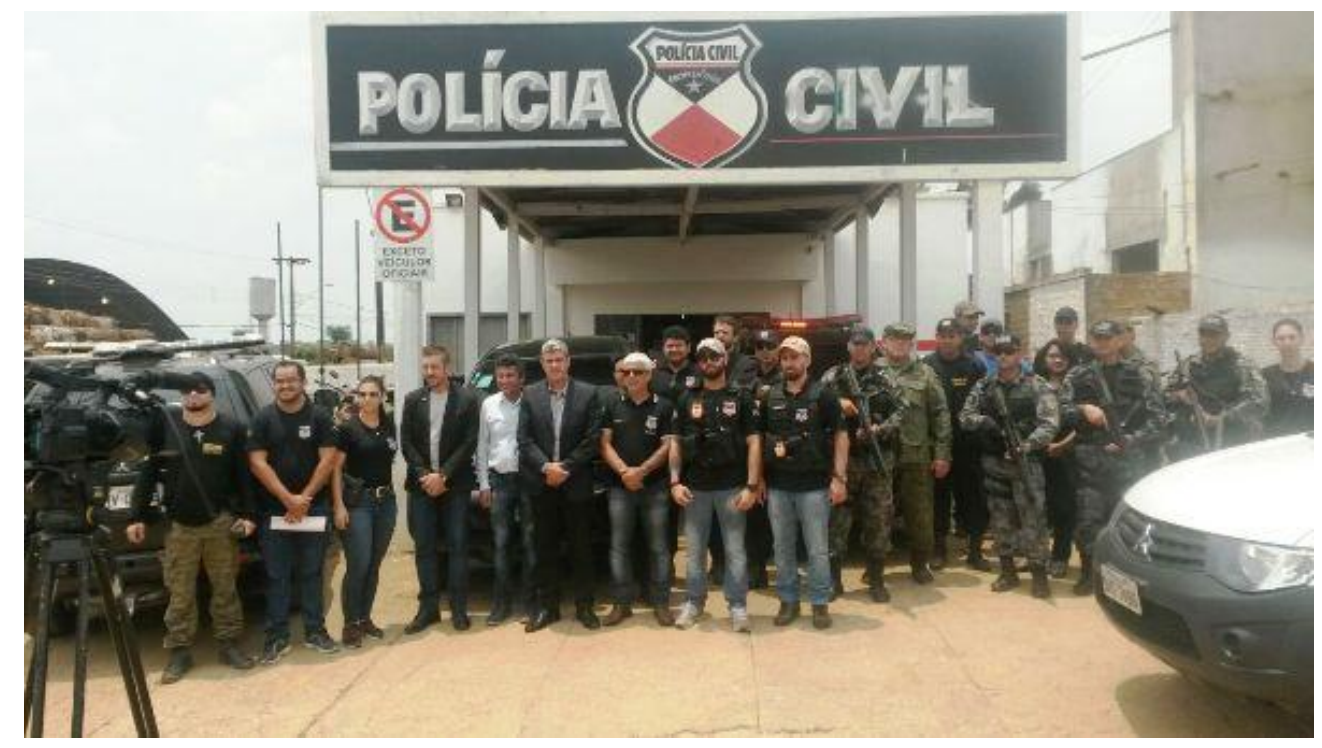

Fonte: Pesquisa de campo junto aos policiais civis envolvidos

\section{Dados colhidos em pesquisa de campo com autoridades policiais}

Nesse ponto da pesquisa, optou-se pela metodologia de entrevistas semiestruturadas com delegados de polícia e demais servidores que atuaram na força-tarefa da região denominada "Vale do Jamary", com intuito de coleta de informações acerca de número de ocorrências no ano de 2017 e ainda dados relevantes sobre investigações e modus operandi das quadrilhas investigadas. Foram entrevistados três delegados de polícia e seis agentes investigadores, além de dois técnicos da Secretaria de Desenvolvimento Ambiental.

Dados colhidos junto às autoridades policiais que atuaram na referida força tarefa denotam que a principal forma de agir dos grupos criminosos daquela região é o corte de árvores em reservas ambientais, a falsificação de licenças florestais e a inserção de dados falsos nos sistemas de controle.

De acordo com dados fornecidos pela Polícia Civil do Estado de Rondônia, no ano de 2017 foram registradas mais de 500 (quinhentas) ocorrências de delitos ambientais na região do Vale do Jamary, que compreende as circunscrições policiais dos municípios de Ariquemes, Buritis, Cujubim, Machadinho do Oeste e Jaru. 
Figura 4 - Focos de ação de organizações criminosas na exploração ilegal de madeira em Rondônia

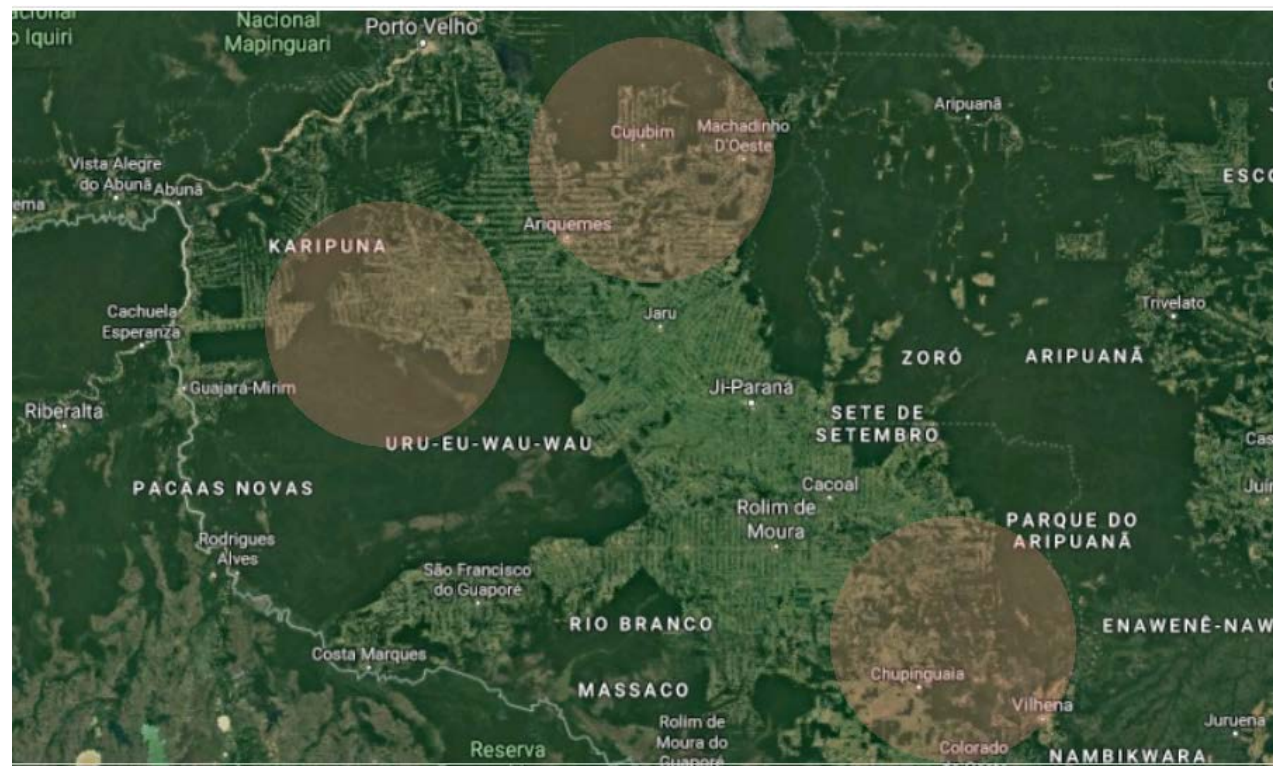

Fonte: Pesquisa de campo junto aos policiais civis envolvidos

De acordo com os delegados de polícia que presidiram as investigações durante a força-tarefa mencionada, no período de trabalho do grupo foram instaurados cerca de 30 (trinta) inquéritos policiais para apuração de crimes ambientais, sendo pelo menos quatro deles decorrentes de ação de Organização Criminosa.

No período, ainda de acordo com as autoridades, cerca de 45 pessoas foram autuadas em flagrante delito e 17 pessoas presas em virtude de mandado de prisão temporária ou preventiva pelos crimes ambientais. Foram deflagradas também cinco operações policiais de grande relevo na região.

As autoridades foram enfáticas em afirmar que a ação de organizações criminosas é predominante na região no que toca à extração ilegal de madeira, e que não se trata de exploração econômica isolada e tampouco de extrativistas desorganizados.

Na microrregião do município de Buritis, por exemplo, onde a referida equipe ficou sediada a maior parte do tempo, segundo informaram os policiais, há uma dependência econômica do próprio município quanto à exploração de madeira, onde cerca de 2000 (duas mil) pessoas estão envolvidas direta ou indiretamente com essa atividade a qual é o principal sustento de suas famílias.

Outro dado importante informado pelos entrevistados é que a exploração ilegal é tão comum na região que as pessoas sequer tem noção que essa atividade seja criminosa. As pessoas são cooptadas para realizar um trabalho braçal de serrar madeira dentro da área florestal, e aceitam por ser eventualmente seu único meio de sustento. 
Conforme mencionado no tópico 3 do presente artigo, isso denota a injustiça social da própria atividade punitiva do estado quanto a esse tipo de delito, pois muitas vezes o indivíduo que atua como extrativista não tem outra alternativa de sobrevivência e sequer enxerga o "trabalho" realizado como uma infração criminal, por outro lado, as empresas madeireiras tem lucro significativo com a exploração de madeira ilegalmente extraída.

A madeira extraída ilegalmente na região do Vale do Jamary é destinada aos estados do sudeste e nordeste, sendo boa parte exportada por se tratar de essências de alto valor comercial.

Questionados sobre o modus operandi das referidas quadrilhas, os entrevistados explicaram minuciosamente a principal estratégia das organizações criminosas, que passamos a expor: A madeira é extraída ilegalmente de áreas de reserva ambiental (APP e UCs) e as empresas madeireiras compram a preços módicos e sem qualquer controle, ampliando o desmatamento na região, com a entrada da madeira no pátio as empresas precisam justificar dentro do sistema de controle (DOF) a origem da madeira, e então inserem dados falsos, se valendo de outras pessoas jurídicas fictícias como supostas fornecedoras da madeira ilegal, então emitem notas fiscais e novas guias (DOF) para revenda (agora legal) da madeira, obtendo altos lucros. Vale dizer que eventualmente contam com a participação de agentes de fiscalização corrompidos.

Figura 5 - Modus Operandi das Organizações Criminosas Ambientais

\section{ENTENDA A FRAUDE}

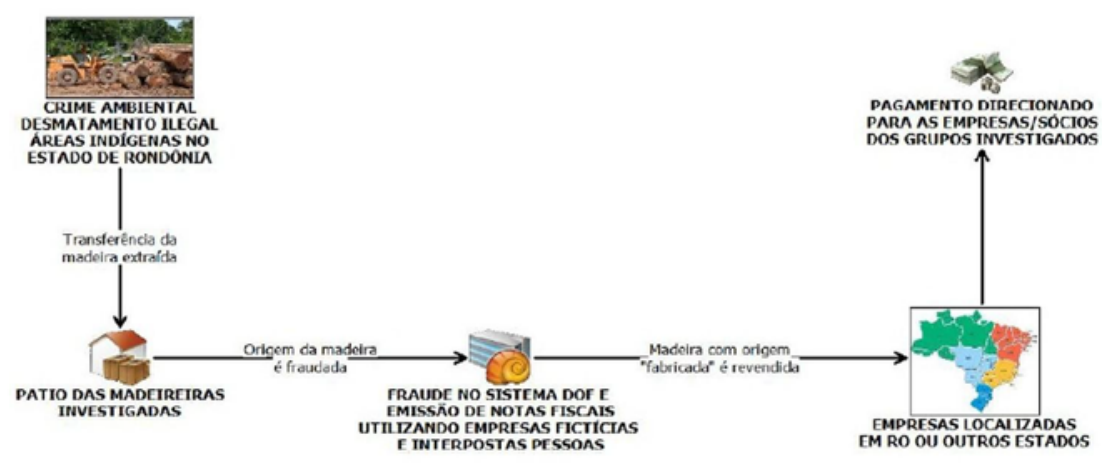

Fonte: Pesquisa de campo junto aos policiais civis envolvidos

Quanto aos crimes praticados por organizações criminosas que atuam na região, os delegados informaram que foram apurados além dos crimes de organização criminosa (art. 2º da lei 12.850/13) e crimes ambientais contra a flora, os crimes de lavagem de capitais (lei 9.613/98), já que o lucro advindo dessa atividade criminosa não são declarados pelas empresas e tampouco pelos sócios-proprietários. 
As ações desses grupos fica conhecida como "Máfia da Madeira" ou "Máfia da Tora", esse inclusive foi o nome dado à operação da Polícia Federal no estado de Rondônia em julho de $2017^{9}$. De acordo com informações da Polícia Federal para a imprensa, a ação criminosa também se dava com inserção de dados falsos nos sistemas de controle (sistema DOF).

\section{CONSIDERAÇÕES FINAIS}

O direito a um meio ambiente equilibrado não só é um direito humano assegurado no âmbito da comunidade internacional por diversos tratados e convenções, é também assegurado como direito fundamental em várias passagens do texto constitucional vigente. Configura direito humano de terceira geração e, na condição de direito fundamental, impõe ao Estado brasileiro um dever de prestação, qual seja, velar para que as gerações futuras tenham acesso aos mesmos recursos naturais hoje existentes ou o mais próximo disso.

Daí o conceito de desenvolvimento sustentável, a ordem econômica deve curvar-se ao direito fundamental a um meio ambiente equilibrado para essa e as futuras gerações. Ações contrárias a essas diretrizes, seja por particulares (pessoas físicas ou jurídicas), seja pelo próprio Estado, são infrações da mais grave monta, eis que atentam contra a própria noção de sobrevivência da humanidade no globo terrestre.

O poder constituinte reunido em 1988 foi sensível ao perceber que a demanda de um meio ambiente equilibrado merecia guarida constitucional e assim o fez como nunca antes na história do Estado brasileiro. As previsões e princípios inaugurados com a ordem constitucional atual serviram e continuarão servindo de base para a evolução do povo brasileiro na sua relação com o meio onde vive.

A proteção criminal do bem jurídico ambiental veio como uma salvaguarda mais efetiva ao meio ambiente, no entanto, em que pese ter sido previsto em 1988, foi levada a cabo somente com a edição da lei de crimes ambientais, dez anos depois. Mesmo que tardiamente, a República Federativa do Brasil ainda cumpriu seu papel em punir condutas lesivas ao meio ambiente, honrando assim os diversos tratados de que é signatária na matéria.

Dentre os crimes ambientais, os crimes contra a flora são aqueles que geram maior lucro para grupos criminosos que exploram a madeira como produto econômico. A invasão de terras públicas para extração de madeira também é algo frequente na Amazônia. Infelizmente a maior parte dos crimes contra a flora são considerados infrações de menor potencial ofensivo, especialmente aqueles geralmente perpetrados por empresários do ramo.

\footnotetext{
${ }^{9}$ Reportagem da operação disponível no link< https://gl.globo.com/ro/guajara-mirim-regiao/noticia/novas-imagens-revelam-
} 
Como criminosos de menor potencial ofensivo, os infratores sequer são autuados em flagrante. Uma situação comum é a captura, pela polícia ou fiscalização ambiental, de caminhões transportando madeira ilegal ou mesmo do encontro de madeira ilegal dentro do pátio de empresas de beneficiamento, ocasióes em que esses criminosos firmam compromisso de comparecerem aos atos do processo e nem mesmo conduzidos à delegacia de polícia eventualmente são.

Situação bem distinta ocorre com o extrativista que tem a atividade de serrador como único meio de sustento para sua prole. Esse sim é tido por criminoso de médio potencial ofensivo, é conduzido e no mais das vezes autuado e recolhido ao cárcere. É o retrato da injustiça social no Brasil, o criminoso de melhor poder aquisitivo nem mesmo conduzido será ao passo que o miserável vai à reclusão juntamente com outros criminosos quaisquer.

Essa impunidade facilita a ação de grupos econômicos e empresários que queiram agir de forma espúria e lesar o meio ambiente, contribuindo para o aumento em progressão aritmética da devastação na Amazônia ocidental.

Essa ação organizada e estruturada, com intuito de obter vantagem econômica lesando ao meio ambiente pode ser considerada ação de organizações criminosas, mormente quando provado que o empreendedor tem o controle finalístico da extração de madeira em área de reserva.Em linhas gerais, uma vez que comprovado o conluio ou relação de hierarquia entre o empreendedor que recebe a madeira e o extrativista, havendo quatro ou mais pessoas cientes e participando da empreitada, devidamente configurado o crime de organização criminosa.

Por outro lado, configurado o delito ambiental, o lucro dele decorrente caso ocultado ou dissimulado, configura o crime de lavagem de capitais, e, por conseguinte, se enquadra dentre um dos delitos comumente denominados "crime do colarinho branco".

Mesmo sem considerar a eventual lavagem de dinheiro, o crime ambiental de extração ilegal de madeiras, quando alcança dimensão transnacional com a exportação da essência ilegalmente extraída, é considerado por organismos internacionais como a INTERPOL um crime de "colarinho branco".

Essa classificação se dá, sobretudo, pelo volume de transações financeiras decorrente da extração ilegal ou clandestina de madeira. São dezenas de bilhões de dólares todos os anos, dinheiro que serve ainda para alimentar redes terroristas ou mesmo o crime organizado transnacional de toda ordem. O crime deve ser compreendido como uma economia paralela, e todas as atividades criminosas estão, portanto, ligadas de forma direta ou indireta.

detalhes-da-operacao-mafia-da-tora-em-rondonia.ghtml>. Acesso em 23 de setembro de 2018. 
A extração ilegal de madeira na Amazônia ocidental, objeto desse estudo, tem sido preponderantemente realizada por organizações criminosas e não por indivíduos isolados como muitos imaginam. A Polícia Civil do Estado de Rondônia e a Polícia Federal, percebendo o volume de crimes dessa natureza tem envidado esforços nos últimos meses para combate a essas organizações e redes criminosas.

Várias foram as operações policiais realizadas, e os policiais envolvidos, entrevistados puderam expor o modus operandi dos criminosos e os resultados obtidos pela ação do Estado nos últimos meses. De acordo com as autoridades, em determinadas localidades da região conhecida como Vale do Jamary o crime ambiental tem forte influencia econômica, sendo um dos pontos de sustento econômico da municipalidade.

As organizações criminosas agem essencialmente com a falsificação de licenças e a inserção de dados falsos nos sistemas de controle ambiental, especialmente no sistema "DOF" que é utilizado tanto pela Secretaria de Desenvolvimento Ambiental do Estado quanto pelo IBAMA.

No ano de 2017, mais de 500 ocorrências foram registradas naquela região dando conta de crimes ambientais, quase todos contra a flora. A força-tarefa que atuou na área também concluiu 30 inquéritos policiais, sendo vários deles acerca da atuação de organizações criminosas na área, o que ensejou a prisão de dezenas de pessoas tanto em flagrante quanto em virtude de mandado judicial.

Como resultado dessa ação criminosa, de outra vertente, tem-se que o desmatamento na Amazônia ocidental mais uma vez aumentou na comparação ano a ano. Os dados do observatório do Instituto Nacional de Pesquisa Espacial indicam o aumento do desmatamento em quilômetros quadrados.

Por tudo isso, fica claro que a ação de organizações criminosas na prática de crimes ambientais pode ser considerado uma espécie de crime de colarinho branco e uma grave violação a direitos humanos, especialmente o direito humano a um meio ambiente equilibrado.

\title{
GREEN CRIMES AND WHITE COLLAR: THE WOOD MAFIA IN THE WESTERN AMAZON, A VIOLATION OF HUMAN RIGHTS
}

\begin{abstract}
This article deals with criminal organizations in the practice of environmental crimes in western Amazonia, with a focus on illegal logging in environmental reserves located in the state of Rondônia. The objective of the research is to present environmental crime for a prism not yet explored, the action of criminal groups and organizations with
\end{abstract}


high profitability to the detriment of the environment and to the detriment of the traditional population, which translates into violation of human rights in several aspects. The research is applied, with a qualitative approach, with data collection from the respective police stations and bibliographical research on the subject. As a result, it is concluded that the clandestine exploitation of wood in environmental reserves is not an occasional or isolated crime, but an action of organized criminal groups with division of tasks, forming real criminal organizations.

Keywords: Wood; Western Amazonia; Environmental Crimes; Criminal organizations; Traditional population.

\section{REFERENCIAS BIBLIOGRÁFICAS}

AGRA, Walber de Moura. Curso de direito constitucional. 8. ed. Rio de Janeiro. Forense. 2014.

ALEIXO, Letícia Soares Peixoto. DIREITO AO MEIO AMBIENTE: UM DIREITO HUMANO?. In: TRINDADE, Antônio Augusto Cançado; LEAL, César Barros. (Org). Direitos Ambiente e Humanos. Fortaleza: Expressão Gráfica e Editora, 2017.p.133-151.

ASCOM. Polícia Civil e SEDAM deflagram operação “Cyber-Cupim” no Vale do Jamary. 2018. Disponível em: <https://www.wwf.org.br/natureza_brasileira/areas_prioritarias/amazonial/ameacas_riscos_amazonia/desm atamento_na_amazonia/extracao_de_madeira_na_amazonia/>.Acesso em: 23 set. 2018

BALTAZARJUNIOR, José Paulo. Crimes Federais.11 ed. São Paulo: Saraiva, 2017.

BARRETO, Paulo; ARAÚJO, Elis; BRITO, Brenda. A impunidade de crimes ambientais em áreas protegidas federais na Amazônia. Belém/ PA. Instituto do Homem e Meio Ambiente da Amazônia, 2009.

BRAGA, Alice Serpa. Tratados internacionais de meio ambiente: estatura no ordenamento jurídico brasileiro. Revista Jus Navigandi, ISSN 1518-4862, Teresina, ano 16, n. 2936, 16 jul. 2011. Disponível em: <https://jus.com.br/artigos/19556>. Acesso em: 22 set. 2018.

BRASIL. Constituição Federal. Disponível 
http://www.planalto.gov.br/ccivil_03/Constituicao/Constituicao.htm Acesso em: 17 de setembro de 2018.

BRASIL. Lei 12.651/2012. Dispõe sobre a proteção da vegetação nativa. Brasilia, DF.

BRASIL. Lei n 9.099, de 26 set 1995. Dispõe sobre os Juizados Especiais Cíveis e Criminais e dá outras providências. Disponível em <http://www.planalto.gov.br/ccivil_03/decreto-lei/del2848.htm Acesso em 23 set 2018.

BRASIL. Senado. Decreto no 5.015, de 12 de março de 2004. Promulga a Convenção das Nações Unidas Contra o Crime Organizado Transnacional. Disponível em: <http://www.planalto.gov.br/ccivil_03/_ato20042006/2004/decreto/d5015.htm> Diário Oficial [da] República Federativa do Brasil, Brasília, DF. Acesso em: 23 de set de 2018.

BRASIL. Decreto-Lei $\mathrm{n}^{\circ}$ 2.848, de 7 de setembro de 1940. Código Penal. Disponível em <http://www.planalto.gov.br/ccivil_03/decreto-lei/del2848.htm Acesso em 23 set 2018.

BRASIL. LEI 9985/00, de 18 de julho de 2000.. Sistema Nacional de Unidades de Conservação da Natureza e dá outras providências.. Disponível em <http://www.planalto.gov.br/ccivil_03/decreto-lei/del2848.htm Acesso em 23 set 2018 .

BRASIL. Lei no 12.850, de 02 de agosto de 2013. Disponível em: < http://www.planalto.gov.br/ccivil_03/_ato2011-2014/2013/lei/112850htm>. Acesso em 23 set 2018.

BRASIL. Lei $\mathrm{n}^{\circ}$ 12.850, de 2 de agosto de 2013. Organização criminosa. Disponível em < http://www.planalto.gov.br/ccivil_03/_ato2011-2014/2013/lei/112850.htm>Acesso em 23 set 2018.

BRASIL. Lei no 4.947, de 6 de abril de 1966. Organização criminosa. Disponível em < http://www.planalto.gov.br/ccivil_03/leis/L4947.htm>Acesso em 23 set 2018.

BRASIL. Lei $\mathrm{n}^{\circ}$ 9.605, de 12 de fevereiro de 1998. Disponível em < http://www.planalto.gov.br/ccivil_03/LEIS/L9605.htm>Acesso em 23 set 2018.

CALIXTRO, Bruno.Em Rondônia, desmatamento é caso de polícia. 2018. Disponível em: 
<https://epoca.globo.com/ciencia-e-meio-ambiente/noticia/2018/01/em-rondonia-desmatamento-e-caso-depolicia.html>. Acesso em: 23 set. 2018.

CARVALHO, Kildare Gonçalves. Direito Constitucional Didático 7. ed. Belo Horizonte: Del Rey, 2001.

$\begin{array}{llll}\text { DECLARAÇÃO } & \text { UNIVERSAL } & \text { DO } & \text { MEIO }\end{array}$ http://www.direitoshumanos.usp.br/index.php/Meio-Ambiente/declaracao-de-estocolmo-sobre-o-ambientehumano.html Acesso em: 17 de setembro de 2018.

FIORILLO, Celso Antonio Pacheco. Curso de Direito Ambiental Brasileiro. 11. ed. São Paulo: Saraiva, 2013. FREITAS, Júnior. Novas imagens revelam detalhes da operação 'Máfia da Tora' em Rondônia. 2017. Disponível em: $\quad$ https://gl.globo.com/ro/guajara-mirim-regiao/noticia/novas-imagens-revelam-detalhes-da-operacaomafia-da-tora-em-rondonia.ghtml. Acesso em: 23 set. 2018.

FREITAS, Vladimir Passos de; FRE ITAS, Gilberto Passos de. Crimes contra a Natureza. 7. ed. São Paulo: Revista dos Tribunais, 2001.

GOMES, Luiz Flávio; MACIEL, Silvio. Meio Ambiente. In: GOMES, Luiz Flávio; CUNHA, Rogério Sanches et al(Org).Legislação Criminal Especial. 2.ed. São Paulo. Revista dos Tribunais. 2010. Cap.13, p.802-963.

GRECO FILHO, Vicente. Comentários à Lei de Organização Criminosa: Lei n. 12.850/13.ed. São Paulo. Saraiva. 2014.

GRUPO DE TRABALHO AMAZÔNICO - GTA REGIONAL RONDÔNIA. O fim da Floresta? A devastação das Unidades de Conservação e Terras Indígenas no Estado de Rondônia. Porto Velho, RO. 60 p. jun. 2008. Disponível em: Acesso em: 23. Set. 2018.

Industrial. Porto Velho-RO. 332 p. 1997

INSTITUTO NACIONAL DE PESQUISAS ESPACIAIS - INPE. Metodologia para o Cálculo de taxa anual de desmatamento na Amazônia Legal. Programa Amazônia - Projeto Prodes. Disponível em: < http://www.obt.inpe.br/prodes/metodologia_TaxaProdes.pdf>.Acesso em: 14.Ago. 2015. 
LEHFELD, Lucas de Souza; CARVALHO, Nathan Castelo Branco de; BALBIM, Leonardo Isper Nassif. Código Florestal Comentado e Anotado: Artigo por Artigo. 3. ed. São Paulo: Método, 2015.

LIMA, Renato Brasileiro de. Legislação criminal especial comentada. volume único I 4. ed. Salvador/BA. JusPODIVM, 2016.

LOPES JR., Aury. Direito processual penal. 13. ed. São Paulo/SP.Saraiva, 2016.

MACHADO, Paulo Affonso Leme. Direito Ambiental Brasileiro. 21.ed. São Paulo. Editora Malheiros, 2013.

MARCÃO, Renato. Crimes Ambientais: Anotações e interpretação jurisprudencial da parte criminal da Lei 9.605/98. 2. ed. São Paulo: Saraiva, 2013.

MESQUITA, Marcel Brugnera. O Federalismo Brasileiro e a Repartição de Competências em Matéria Ambiental. In: VITORELLI, Edilson et al. (Org.). Temas Aprofundados do Ministério Público Federal. 2. ed. Salvador/BA: Juspodivm, 2013. cap. 16, p. 405-422.

MILARÉ, Édis. Direito do ambiente: doutrina, jurisprudência. São Paulo. Revista dos Tribuanais.2007.

MORO, Sergio Fernando. Crime de lavagem de dinheiro. São Paulo. Saraiva, 2010.

PEREIRA, Juvenal. Destruir a terra para alimentar a fome insaciável por madeira. Disponível em: $<$ https://www.wwf.org.br/natureza_brasileira/areas_prioritarias/amazonial/ameacas_riscos_amazonia/desm atamento_na_amazonia/extracao_de_madeira_na_amazonia/>. Acesso em: 23 set. 2018.

PIMENTEL, Manoel P. O Crime de Colarinho Branco. São Paulo: Lex, Julgados do Tribunal de Alçada Criminal de São Paulo, 1974. Disponível em <http://www.revistas.usp.br/rfdusp/article/download/66692/69302>. Acesso em: 23 de setembro de 2018.

QUEIROZ, Carlos Alberto Marchi de, Crime organizado no Brasil: comentários à Lei no 9.034/95 : aspectos 
policiais e judiciários : teoria e prática. - São Paulo: Iglu, 1998.

RAMOS, André de Carvalho. Curso de direitos humanos. 4. ed. São Paulo. Saraiva. 2017.

SARLET, Ingo; MARINONI, Luiz Guilherme; MITIDIERO, Daniel. Curso de direito constitucional. 4. ed. São Paulo. Saraiva. 2015

SILVA, José Afonso da. Curso de Direito Constitucional Positivo. 37a edição, revista e atualizada até a Emenda Constitucional n. 76, de 28.11.2013. São Paulo. Editora Malheiros. 2014.

SIRVINSKAS, Luís Paulo. Manual de direito ambiental. São Paulo: Saraiva, 2002.

SOUZA, Artur de Brito Gueiros. JAPIASSÚ, Carlos Eduardo Adriano. Curso de direito penal: parte geral. Rio de Janeiro. Elsevier. 2011.

WORLD BANK, The World Bank Participation Sour ticipation Sourcebook. Washington, DC: World Bank cebook (International Bank of Reconstruction and Development), 1996.

Trabalho enviado em 24 de setembro de 2018

Aceito em 03 de setembro de 2018 